\title{
위암의 최소침습수술
}

\author{
박도중, 안상훈, 김형호 \\ 서울대학교 의과대학 외과학교실, 분당서울대학교병원 외과
}

\section{Minimally invasive surgery in gastric cancer}

\author{
Do Joong Park, Sang Hoon Ahn, Hyung-Ho Kim \\ Department of Surgery, Seoul National University Bundang Hospital, Seoul National University College of Medicine, Seoul, Korea
}

Gastric cancer surgery with curative intent comprises subtotal or total gastrectomy with radical lymph node dissection. Recently, as the incidence of early gastric cancer (EGC) is increasing, minimally invasive surgery can be applied to gastric cancer treatment. Minimally invasive gastric surgery has four aspects such as minimally invasive access, modified function-preserving gastrectomy, limited lymphadenectomy, and no reconstruction. Laparoscopic gastrectomy became popular for EGC and its indication is being expanded to advanced gastric cancer. Reduced or single port gastrectomy can be performed for selective EGC. For middle or upper EGC, laparoscopic pylorus-preserving gastrectomy or proximal gastrectomy is applicable as function-presenving gastrectomy. D1+ node dissection is enough for EGC without lymph node metastasis and sentinel node biopsy will be helpful for avoiding unnecessary lymph node dissection in EGC patients.

Keywords: Gastric cancer, Minimally invasive surgery, Laparoscopy, Sentinel lymph node

\section{서 론}

위암은 우리나라에서 두 번째로 흔한 암이며 사망률도 폐암, 간암에 이어 세 번째로 높다[1]. 위암의 치료에 있어서 수술은 근치적 치료 의 가장 중요한 방법이며 근치적 위암 수술은 광범위한 위 및 림프 절 절제를 필요로 한다. 위암 수술은 1881년 Billroth가 처음으로 성 공적으로 시행한 이후 위암 발생이 많은 한국, 일본을 중심으로 많 은 발전이 있어 왔다. 20세기 후반에 복강경 수술 기법이 도입되면 서 위암에서도 1991년에 복강경 위암 수술을 성공적으로 시행하게 되었다.

최근 국가암검진사업으로 위내시경이 활발하게 시행됨에 따라 조기 위암의 발견이 증가하였다. 따라서 복강경 위암수술이 활발하

Received: Dec 15, 2015 Accepted: Dec 21, 2015

Correspondence to: Do Joong Park

Department of Surgery, Seoul National University Bundang Hospital,

Seoul National University College of Medicine, 82 Gumi-ro 173beon-gil, Bundang-gu, Seongnam 13620, Korea

Tel: +82-31-787-7097, Fax: +82-31-787-4055

E-mail: djpark@snubh.org

Copyright (C) Korean Society of Surgical Oncology

This is an Open Access article distributed under the terms of the Creative Commons Attribution Non-Commercial License (http://creativecommons.org/licenses/by-nc/3.0) which permits unrestricted non-commercial use, distribution, and reproduction in any medium, provided the original work is properly cited.
게 시행되고 일부 조기 위암 환자에게는 축소공 또는 단일공 수술도 가능하게 되었다. 또한 절제 범위도 축소되어 위를 보존하는 기능보 존 위 절제술이 가능하게 되었는데, 중부 조기 위암에서는 유문보존 위 절제술이, 그리고 상부 조기 위암에서는 근위부 위 절제술이 시 행되었다. 림프절 절제 범위도 기존의 D2 림프절 절제에서 조기 위 암의 경우에 $\mathrm{D} 1+$ 절제로 축소되고 감시림프절 개념을 위암 수술에 서도 적용하고자 하는 노력이 계속되고 있다.

이에 저자들은 현재 위암 치료에 시행되고 있는 최소침습수술의 최신 지견을 최소침습접근(minimally invasive access), 기능보존 위 절제(function-preserving gastrectomy), 축소 림프절 절제(limited lymph node dissection), 수술 후 조기 회복(enhanced recovery after surgery, ERAS) 프로그램 부분으로 나누어 문헌고찰과 저자들의 경 험을 바탕으로 정리하고자 한다.

\section{본 론}

\section{최소침습접근(Minimally invasive access) 복강경 위암 수술(Laparoscopic gastrectomy)}

1991년 Kitano 등 [2]이 조기 위암에서 복강경 위암 수술을 처음 시행 한 이후로 조기 위암에서 복강경 위암수술은 해마다 증가해 왔으며 많은 발전이 있었다. 복강경 수술의 장점으로는 수술 후 통증, 염증 반응 및 합병증이 적고 회복이 빠르다고 할 수 있다[3]. 현재 조기 위 
암에서의 복강경 위암 수술의 효용성을 평가하기 위한 대규모의 다 기관 전향적 무작위 비교 연구가 진행 중이다(Table 1). 한국에서 진 행되고 있는 Korean Laparoscopic Gastrointestinal Surgery Study (KLASS) 01 연구는 2006년부터 2010년까지 등록된 1,416명의 cT1$2 \mathrm{~N} 0$ 위암 환자를 대상으로 복강경과 개복 원위부 위 절제술을 비교 하는 연구로서 최종 결과인 5년 생존율이 2015년에 나올 예정이다 [4]. 일본의 Japan Clinical Oncology Group (JCOG) 0912는 I기 위암 환자 920 명을 대상으로 2010년부터 시작된 연구이다[5]. 이전에 보 고된 작은 규모의 전향적 비교연구도 있었지만[6], 최근의 두 연구 가 조기 위암에서의 복강경수술의 효용성을 입증해 줄 것으로 기대 한다.

복강경 수술의 술기와 기구가 발전함에 따라 복강경 수술의 적응 증을 진행위암까지 확대하고자 하는 노력이 진행되고 있다. Park 등 [7]의 239 명의 진행성 위암 환자를 대상으로 시행한 다기관 후향적 연구에 의하면 복강경 위암 수술 후 장기 생존결과는 개복 위암 수
술의 결과와 비슷하였다. 현재 진행위암에서 진행되고 있는 3상 연 구는 한국의 KLASS 02, 일본의 Japanese Laparoscopic Surgery Study Group (JLSSG) 0901, 중국의 Chinese Laparoscopic Gastrointestinal Surgery Study (CLASS) 01이 있다(Table 1). KLASS 02는 1,050명의 cT2-4a 위암 환자를 대상으로 복강경과 개복 위암 수술 후 3 년 무재 발 생존율을 평가하는 연구이며 이 결과는 향후 진행위암에서 복강 경 수술의 적용을 확대하는 중요한 근거가 될 것이다[8].

다른 한편으로는, 절제 불가능한 4 기 위암 환자에서 항암치료 후 절제 가능하게 전환되어 근치적 수술을 하는 전환 수술(conversion surgery)에서 복강경 위 수술을 시행하여 수술 후 적시에 항암치료 가 이어지도록 도움을 주는 역할에 대한 연구도 이루어지고 있다.

\section{축소공 및 단일공 위암 수술(Reduced or single port gastrectomy)} 개복 위암 수술에서 복강경 위암 수술로의 발전이 있었고, 최근에는 자연 개구부를 통하여 복강 내로 접근하는 방법(natural orifice

Table 1. Current clinical trials on minimally invasive surgery in gastric cancer

\begin{tabular}{llllllll}
\hline Study & Year & Nation & Phase & Design & Patients & Enroll & Primary endpoint \\
\hline KLASS 01 & 2005 & Korea & III & LDG vs. ODG & cStage I & 1,400 & 5-year overall survival \\
KLASS 02 & 2011 & Korea & III & LDG vs. ODG & cT2-4a & 1,050 & 3-year relapse-free survival \\
KLASS 03 & 2012 & Korea & II & LTG for EGC & Stage I & 168 & Morbidity, motality \\
KLASS 04 & 2014 & Korea & III & LPPG vs. LDG & Stage I & 256 & Dumping syndrome \\
KLASS 05 & 2015 & Korea & III & LPG vs. LTG & Stage I & 180 & Hemoglobin change \\
JCOG 0912 & 2010 & Japan & III & LDG vs. ODG & Stage I & 920 & 5-year overall survival \\
JLSSG 0901 & 2010 & Japan & II/III & LDG vs. ODG & cT2-4a & $180 / 500$ & Mobidity/relapse-free survival \\
CLASS 01 & 2012 & China & III & LDG vs. ODG & cT2-4a & 1,056 & 3-year relapse-free survival \\
\hline
\end{tabular}

KLASS, Korean Laparoscopic Gastrointestinal Surgery Study; LDG, laparoscopic distal gastrectomy; ODG, open distal gastrectomy; LTG, laparoscopic total gastrectomy; EGC, early gastric cancer; LPPG, laparoscopic pylorus-preserving gastrectomy; LPG, laparoscopic proximal gastrectomy; JCOG, Japan Clinical Oncology Group; CLASS, Chinese Laparoscopic Gastrointestinal Surgery Study.

Table 2. Studies on single port gastrectomy

\begin{tabular}{|c|c|c|c|c|c|c|c|}
\hline Author & Year & Nation & $\mathrm{N}$ & Journal & Method & Results & Characteristics \\
\hline Omori et al. [9] & 2011 & Japan & 7 & Surg Endosc & $\begin{array}{l}2.5 \mathrm{~cm} \text { incision } \\
\text { Two } 2 \mathrm{~mm} \text { assistant ports }\end{array}$ & $\begin{array}{l}\text { Operation time: } 344 \text { minutes } \\
\text { Estimated blood loss: } 25 \mathrm{~mL} \\
\text { Examined lymph nodes: } 67 \\
\text { No major complication }\end{array}$ & $\begin{array}{l}\text { Distal gastrectomy } \\
\text { Billroth I }\end{array}$ \\
\hline Park et al. [10] & 2012 & Korea & 2 & $\begin{array}{l}\text { Surg Laparosc } \\
\text { Endosc Percutan Tech }\end{array}$ & $\begin{array}{l}2.5 \mathrm{~cm} \text { incision } \\
\text { One } 2 \mathrm{~mm} \text { assistant port }\end{array}$ & $\begin{array}{l}\text { Operation time: } 275 \text { minutes } \\
\text { Estimated blood loss: } 85 \mathrm{~mL} \\
\text { Examined lymph nodes: } 32 \\
\text { No major complication }\end{array}$ & $\begin{array}{l}\text { Distal gastrectomy } \\
\text { Billroth I }\end{array}$ \\
\hline Ahn et al. [11] & 2013 & Korea & 22 & J Am Coll Surg & $\begin{array}{l}2.5 \mathrm{~cm} \text { incision } \\
\text { No assistant port }\end{array}$ & $\begin{array}{l}\text { Operation time: } 178 \text { minutes } \\
\text { No major complication }\end{array}$ & $\begin{array}{l}\text { Distal gastrectomy } \\
\text { Uncut Roux-en-Y }\end{array}$ \\
\hline Ahn et al. [12] & 2014 & Korea & $\begin{array}{c}50 \\
50 \\
\text { (control) }\end{array}$ & J Am Coll Surg & $\begin{array}{l}2.5 \mathrm{~cm} \text { incision } \\
\text { No assistant port }\end{array}$ & $\begin{array}{l}\text { Operation time: } 144 \text { minutes } \\
\text { Estimated blood loss: } 50 \mathrm{~mL} \\
\text { Examined lymph nodes: } 52\end{array}$ & $\begin{array}{l}\text { Distal gastrectomy } \\
\text { Billroth I, Uncut Roux-en-Y } \\
\text { Comparative study }\end{array}$ \\
\hline Ahn et al. [13] & 2014 & Korea & 2 & Gastric Cancer & $2.5 \mathrm{~cm}$ incision & $\begin{array}{l}\text { Operation time: } 190 \text { minutes } \\
\text { Estimated blood loss: } 55 \mathrm{~mL} \\
\text { Examined lymph nodes: } 77 \\
\text { No major complication }\end{array}$ & Total gastrectomy \\
\hline
\end{tabular}


transluminal endoscopic surgery, NOTES)에 대하여 많은 전임상 및 임상 연구가 진행되고 있다[14]. 하지만 아직은 임상에 적용할 정도 의 근거를 가지지는 못하고 있다. 그 중간 단계로 축소공(reduced port) 또는 단일공(single port) 수술이 활발하게 연구가 되고 있고 담 낭 절제술, 충수돌기 절제술 등 양성 질환에 대하여 점차적으로 많 이 시행되고 있다[15]. 하지만 아직 위암에서의 축소공 또는 단일공 수술은 아직 보고가 많지 않은데, 복강경 경험이 많은 몇 개의 기관 에서 조기 위암에서의 단일공 수술을 보고하고 있다(Table 2) [912,16-19]. Ahn 등[12]에 의하면 단일공 수술을 받은 환자들이 기존 의 복강경 수술을 받은 환자들에 비하여 미용적인 만족도가 높았고 출혈량과 수술 당일 및 익일의 수술 후 통증이 적었다고 보고를 하 였다. 향후 단일공 위암 수술에 대한 연구가 연구회를 통하여 계속 활발하게 이어질 것으로 기대한다.

\section{기능보존 위 절제(Function-preserving gastrectomy)}

위암의 근치적인수술로는 위 아전 절제와 위 전 절제만이 있었지만 최근 조기 위암의 증가로 인하여 위의 절제 범위도 줄어들게 되었 다. 조기 위암에서는 약 $2 \mathrm{~cm}$ 정도의 절제연을 확보하면 되기 때문 에 위 아전 절제에서 원위부 위 절제술로 명칭도 바뀌었으며 조기 위암의 위치에 따라서 기능보존 위절제술도 가능해졌다.

\section{유문보존 위 절제술(Pylorus-preserving gastrectomy)}

유문보존 위 절제술은 대표적인 기능보존 위 절제술 중의 하나로서 Maki 등[20]에 의하여 1967년 위 궤양의 수술적 치료 방법으로 소개 되었다. 유문을 보존하기 위하여 1 번, 5 번, 12 번 림프절 절제가 불가 능하므로 위암에서는 그 림프절에 전이가 없다고 예상되는 중부 조 기 위암에서 선택적으로 적용이 가능하다. 유문보존 위 절제술은 기 존의 원위부 위 절제술에 비하여 유문을 보존함으로써 덤핑증후군 과 담즙역류와 같은 위 절제 후에 생길 수 있는 여러 가지 소화기 증 상을 줄여주고, 미주신경 간분지를 보존함으로써 담석의 발생을 줄 여 준다는 장점이 있다[21,22]. 반면에 유문보존 위 절제술은 수술 후 위 배출 지연을 유발시킨다는 보고도 있다[23]. 하지만 이와 같은 보고들은 모두 후향적 연구이며, 따라서 유문보존 위 절제술에 대한 장점을 입증하기 위하여 현재 다기관 전향적 무작위 비교 연구인 KLASS 04 가 진행 중이다. KLASS 04는 유문보존 위 절제술과 기존 의 원위부 위 절제술 간에 일차 유효성 평가 변수인 수술 후 덤핑증
후군 발생의 차이를 비교하고 이차적인 변수로서 영양, 삶의 질, 담 석 발생률 등을 비교할 것이다.

\section{근위부 위 절제술(Proximal gastrectomy)}

상부에 생기는 위암의 경우 위 전 절제술이 표준 수술이었다. 최근 건강검진 위내시경의 시행으로 조기 위암이 증가하고 또한 서구와 같이 상부 위암이 증가하고 있다[24]. 상부에 생긴 조기 위암의 경우 원위부 위 주위의 림프절 전이는 드물기 때문에 근위부 위 절제술 만으로도 위전절제술과 같은 장기 생존율을 가진다고 보고하고 있 다 $[11,25,26]$. 또한 근위부 위 절제술은 위 전절제술에 비하여 영양 이 좋고 빈혈이 적으며 위장관 호르몬 분비 면에서 장점을 가진다고 알려져 있다[27,28]. 그런데 국내 전국조사에 의하면 근위부 위절제 술은 2004년 1.1\%, 2009년에 1.0\%밖에 시행되지 않았다[24]. 근위부 위절제술이 여러 가지 이론적인 장점을 가지고 있음에도 불구하고 많이 시행되지 않는 이유는 후기 합병증인 위식도 역류와 그로 인한 궤양 및 협착 때문이다[11,29]. 근위부 절제를 시행한 후 식도와 잔 위를 바로 이어주는 식도-위 문합 후에 위식도 역류문제가 심각하 기 때문에 많은 술자들이 식도-위 문합에 여러 가지 방법을 추가해 보았지만 일관되게 위식도 역류를 해결하지는 못하였다[29]. 따라 서 식도와 잔위를 바로 이어주지 않고 소장을 삽입하여 식도-소장잔위를 이어주는 문합을 비롯하여 식도-소장을 이어 준 후 잔위를 $10-15 \mathrm{~cm}$ 하방에 이어주는 이중통로문합(double tract reconstruction)도 시행하게 되었다[30]. Ahn 등[30]은 근위부 위 절제술 후 이 중통로문합을 하였을 때 위식도 역류증상이 위 전 절제술 하였을 때 와 비슷하게 적었음을 보고하였다. 따라서상부 조기 위암의 치료로 서 근위부 위 절제술이 표준 치료로 인정받기 위해서 3 상 비교 연구 가 필요하게 되었고 현재 상부 조기 위암에서 복강경하 근위부 위 절제술 후 이중통로문합과 복강경 위 전 절제술을 비교하는 전향적 무작위 비교 연구인 KLASS 05 연구가 진행 중에 있다.

\section{축소 림프절 절제(Limited lymphadenectomy)}

위암의 근치적 수술에서 가장 중요한 요소는 광범위한 림프절 절제 이다. 현재 진행위암에서는 $16 \mathrm{a} 2 / \mathrm{b} 1$ 에 전이가 의심되지 않는다면 예방적인 $\mathrm{D} 2+$ 대동맥주위 림프절 절제는 불필요하며 $\mathrm{D} 2$ 림프절 절 제가 표준 수술로 인정받고 있다[31]. 조기 위암에서는 D1+ 림프절 절제만으로도 근치적인 수술로 받아 들여지고 있다[32]. 조기 위암

Table 3. Clinical trials on sentinel node mapping

\begin{tabular}{lcccccccc}
\hline Study & Year & Nation & Phase & Design & Patients & N & Primary endpoint & Status \\
\hline JCOG 0302 & $2004-2005$ & Japan & $\|$ & Single arm, open & $T 1<4 \mathrm{~cm}$ & $440 / 1,550$ & False negative rate & Terminated \\
JSSNNS & $2004-2008$ & Japan & $\|$ & Single arm, open & $\mathrm{cT} 1,2<4 \mathrm{~cm}$ & 300 & Sensitivity \\
$\begin{array}{l}\text { Laparoscopic } \\
\text { SNNS }\end{array}$ & $2010-2013$ & Korea & $\|$ & Single arm, laparoscopy & $\mathrm{cT} 1<4 \mathrm{~cm}$ & 100 & 3-year disease-free survival & Follow-up \\
SENORITA & 2013- & Korea & III & $\begin{array}{c}\text { Open label, double arm, } \\
\text { laparoscopy, SNNS vs. LDG }\end{array}$ & $\mathrm{cT} 1<3 \mathrm{~cm}$ & 580 & 3-year disease-free survival & Recruiting \\
\hline
\end{tabular}

JCOG, Japan Clinical Oncology Group; JSSNNS, Japanese society of Sentinel Node Navigation Surgery; SNNS, sentinel node navigation surgery; SENORITA, sentinel node oriented tailored approach; LDG, laparoscopic distal gastrectomy. 
중에 점막암인 경우에 림프절 전이율은 $5 \%$ 이내이고 점막하암인 경우에는 15\%-20\%가 림프절 전이가 있다고 알려져 있다. 따라서 조기 위암일 경우 약 $80 \%$ 이상에서 불필요한 광범위 위 절제 및 림 프절 절제를 시행하고 있다. 조기 위암의 경우 절제연을 $2 \mathrm{~cm}$ 이하 로 하고 림프절 절제도 $\mathrm{D} 1+$ 정도로 축소되었지만 내시경점막하 절 제술에 비하면 여전히 광범위 위 절제 및 림프절 절제라고 볼 수 있 다. 만일 조기 위암 환자에서 림프절 전이 여부를 정확하게 알 수 있 다면 불필요한 광범위 절제를 피할 수 있겠지만, 현재 수술 전 시행 하고 있는 위내시경 또는 위내시경초음파, CT 검사로는 림프절 전 이 여부를 $100 \%$ 정확하게 알지 못하기 때문에 광범위 절제가 불가 피한 현실이다. 감시림프절이란 원발암으로부터 림프절 전이가 일 어나는 첫 번째 림프절을 의미한다. 따라서감시림프절의 전이 여부 를 조사하여 전이가 없다면 다른 두 번째 세 번째, 그 이후의 림프절 에도 전이가 없기 때문에 불필요한 림프절 곽청을 피할 수가 있다. 현재 유방암과 악성 흑색종에서는 활발하게 감시림프절 생검이 이 루어지고 있고 많은 환자들이 불필요한 림프절 곽청을 생략함으로 써 림프부종, 감각이상, 운동 장애 등의 합병증을 피할 수 있게 되었 다. 위암은 유방암과 악성 흑색종과 달리 림프절 경로가 복잡하여 감시림프절 생검의 적용이 어렵다고 생각하였으나 많은 연구에서 긍정적인 결과들이 나오게 되었다[33-37]. 현재 진행되고 있는 2상 또는 3상 연구는 Table 3 과 같으며 이들의 결과에 따라 조기 위암에 서감시림프절 생검의 적용이 표준 술식으로 자리잡을 수 있는 계기 를 마련하게 될 것이다.

수술 후 조기 회복(Enhanced or early recovery after surgery) 수술 후 조기 회복 프로그램은 여러 외과 수술 분야, 특히 대장항문 수술에서 수술 후 회복을 향상시키기 위하여 연구가 많이 되었지만 아직 위암 수술 분야에는 보고가 적다. 몇 저자들의 보고에 의하면 위암 수술 후에도 enhanced or early recovery after surgery (ERAS) 프 로그램 적용이 가능하며 국소적인 합병증이 적었다고 하였다 [38,39]. 최근 97명의 복강경 위암 수술을 받은 환자들을 대상으로 ERAS군 $(\mathrm{n}=46)$ 과 그렇지 않은 군 $(\mathrm{n}=51)$ 으로 무작위 배정을 하여 비교하였을 때 ERAS군에서 수술 후 회복률과 시간이 더 빨랐고 통 증이 적었다는 좋은 결과가 미국복강경학회에서 발표되었다[40].

\section{결 론}

위암의 치료에서 최소침습수술은 접근 방법, 위 절제, 림프절 절제 범위 면에서 다양하게 적용이 되고 있다. 접근 방법 면에서는 복강경 위암 수술의 많은 발전이 있었으며 조기 위암뿐만이 아니라 진행위 암으로도 복강경 위암수술의 적응증이 확대되고 있다. 특히 조기 위 암의 경우에는 축소공 또는 단일공 수술을 선택적으로 적용할 수 있 다. 위 절제 범위에서는 중부 조기 위암에서 유문보존 위 절제술을, 상부 조기 위암에서는 근위부 위절제술을 시행할 수 있겠다. 림프절 절제 범위에서는 조기 위암의 경우 D1+ 림프절 절제가 가능하며, 가 까운 미래에 감시림프절 생검의 3 상 시험이 긍정적인 결과가 나오 면 감시림프절 전이가 없는 조기 위암은 국소 위 절제만으로도 근치
적인 치료가 될 것이다. 또한 수술 후 조기 회복 프로그램으로 위암 수술 후 환자의 회복률을 향상시킬 수 있을 것으로 기대한다.

\section{CONFLICT OF INTEREST}

No potential conflict of interest relevant to this article was reported.

\section{REFERENCES}

1. Jung KW, Won YJ, Kong HJ, Oh CM, Cho H, Lee DH, et al. Cancer statistics in Korea: incidence, mortality, survival, and prevalence in 2012. Cancer Res Treat 2015;47:127-41.

2. Kitano S, Maeo S, Shiraishi N, Shimoda K, Miyahara M, Bandoh T, et al. Laparoscopically assisted distal partial gastrectomy for early-stage gastric carcinomas. Surg Technol Int 1995;lv:115-9.

3. Lee SI, Choi YS, Park DJ, Kim HH, Yang HK, Kim MC. Comparative study of laparoscopy-assisted distal gastrectomy and open distal gastrectomy. J Am Coll Surg 2006;202:874-80.

4. Kim HH, Han SU, Kim MC, Hyung WJ, Kim W, Lee HJ, et al. Prospective randomized controlled trial (phase III) to comparing laparoscopic distal gastrectomy with open distal gastrectomy for gastric adenocarcinoma (KLASS 01). J Korean Surg Soc 2013;84: 123-30.

5. Nakamura K, Katai H, Mizusawa J, Yoshikawa T, Ando M, Terashima $\mathrm{M}$, et al. A phase III study of laparoscopy-assisted versus open distal gastrectomy with nodal dissection for clinical stage IA/IB gastric Cancer (JCOG0912). Jpn J Clin Oncol 2013;43:324-7.

6. Huscher CG, Mingoli A, Sgarzini G, Sansonetti A, Di Paola M, Recher $A$, et al. Laparoscopic versus open subtotal gastrectomy for distal gastric cancer: five-year results of a randomized prospective trial. Ann Surg 2005;241:232-7.

7. Park DJ, Han SU, Hyung WJ, Kim MC, Kim W, Ryu SY, et al. Longterm outcomes after laparoscopy-assisted gastrectomy for advanced gastric cancer: a large-scale multicenter retrospective study. Surg Endosc 2012;26:1548-53.

8. Hur H, Lee HY, Lee HJ, Kim MC, Hyung WJ, Park YK, et al. Efficacy of laparoscopic subtotal gastrectomy with D2 lymphadenectomy for locally advanced gastric cancer: the protocol of the KLASS-02 multicenter randomized controlled clinical trial. BMC Cancer 2015; 15:355.

9. Omori $T$, Oyama $T$, Akamatsu $H_{\text {, Tori }} M$, Ueshima $S$, Nishida $T$. Transumbilical single-incision laparoscopic distal gastrectomy for early gastric cancer. Surg Endosc 2011;25:2400-4.

10. Park DJ, Lee JH, Ahn SH, Eng AK, Kim HH. Single-port laparoscopic distal gastrectomy with D1+beta lymph node dissection for gastric cancers: report of 2 cases. Surg Laparosc Endosc Percutan Tech 2012;22:e214-6. 
11. Ahn SH, Lee JH, Park DJ, Kim HH. Comparative study of clinical outcomes between laparoscopy-assisted proximal gastrectomy (LAPG) and laparoscopy-assisted total gastrectomy (LATG) for proximal gastric cancer. Gastric Cancer 2013;16:282-9.

12. Ahn SH, Son SY, Jung DH, Park DJ, Kim HH. Pure single-port laparoscopic distal gastrectomy for early gastric cancer: comparative study with multi-port laparoscopic distal gastrectomy. J Am Coll Surg 2014;219:933-43.

13. Ahn SH, Park DJ, Son SY, Lee CM, Kim HH. Single-incision laparoscopic total gastrectomy with D1+beta lymph node dissection for proximal early gastric cancer. Gastric Cancer 2014;17:392-6.

14. Gumbs AA, Fowler D, Milone L, Evanko JC, Ude AO, Stevens $P$, et al. Transvaginal natural orifice translumenal endoscopic surgery cholecystectomy: early evolution of the technique. Ann Surg 2009; 249:908-12.

15. Pfluke JM, Parker M, Stauffer JA, Paetau AA, Bowers SP, Asbun HJ, et al. Laparoscopic surgery performed through a single incision: a systematic review of the current literature. J Am Coll Surg 2011; 212:113-8.

16. Kawamura H, Tanioka T, Kuji M, Tahara M, Takahashi M. The initial experience of dual port laparoscopy-assisted total gastrectomy as a reduced port surgery for total gastrectomy. Gastric Cancer 2013; 16:602-8.

17. Kunisaki C, Ono HA, Oshima T, Makino H, Akiyama H, Endo I. Relevance of reduced-port laparoscopic distal gastrectomy for gastric cancer: a pilot study. Dig Surg 2012;29:261-8.

18. Lee JH, Lee MS, Kim HH, Park DJ, Lee HJ, Yang HK, et al. Comparison of single-incision laparoscopic distal gastrectomy and laparoscopic distal gastrectomy for gastric cancer in a porcine model. J Laparoendosc Adv Surg Tech A 2011;21:935-40.

19. Ahn SH, Son SY, Lee CM, Jung DH, Park DJ, Kim HH. Intracorporeal uncut Roux-en-Y gastrojejunostomy reconstruction in pure single-incision laparoscopic distal gastrectomy for early gastric cancer: unaided stapling closure. J Am Coll Surg 2014;218:e17-21.

20. Maki T, Shiratori T, Hatafuku T, Sugawara K. Pylorus-preserving gastrectomy as an improved operation for gastric ulcer. Surgery 1967;61:838-45.

21. Park DJ, Lee HJ, Jung HC, Kim WH, Lee KU, Yang HK. Clinical outcome of pylorus-preserving gastrectomy in gastric cancer in comparison with conventional distal gastrectomy with Billroth I anastomosis. World J Surg 2008;32:1029-36.

22. Suh YS, Han DS, Kong SH, Kwon S, Shin Cl, Kim WH, et al. Laparoscopy-assisted pylorus-preserving gastrectomy is better than laparoscopy-assisted distal gastrectomy for middle-third early gastric cancer. Ann Surg 2014;259:485-93.

23. Tomita $R$, Takizawa $H$, Tanjoh K. Physiologic effects of cisapride on gastric emptying after pylorus-preserving gastrectomy for early gastric cancer. World J Surg 1998;22:35-40.

24. Jeong 0, Park YK. Clinicopathological features and surgical treatment of gastric cancer in South Korea: the results of 2009 nationwide survey on surgically treated gastric cancer patients. J Gastric Cancer 2011;11:69-77.

25. Nozaki I, Hato S, Kobatake T, Ohta K, Kubo Y, Kurita A. Long-term outcome after proximal gastrectomy with jejunal interposition for gastric cancer compared with total gastrectomy. World I Surg 2013;37:558-64.

26. Ichikawa D, Komatsu S, Kubota T, Okamoto K, Shiozaki A, Fujiwara $\mathrm{H}$, et al. Long-term outcomes of patients who underwent limited proximal gastrectomy. Gastric Cancer 2014;17:141-5.

27. Masuzawa T, Takiguchi $S_{1}$ Hirao $M_{1}$ Imamura $H_{1}$ Kimura Y, Fujita J, et al. Comparison of perioperative and long-term outcomes of total and proximal gastrectomy for early gastric cancer: a multi-institutional retrospective study. World J Surg 2014;38:1100-6.

28. Takiguchi N, Takahashi M, Ikeda M, Inagawa S, Ueda S, Nobuoka T, et al. Long-term quality-of-life comparison of total gastrectomy and proximal gastrectomy by postgastrectomy syndrome assessment scale (PGSAS-45): a nationwide multi-institutional study. Gastric Cancer 2015;18:407-16.

29. Jung DH, Ahn SH, Park DJ, Kim HH. Proximal Gastrectomy for Gastric Cancer. J Gastric Cancer 2015;15:77-86.

30. Ahn SH, Jung DH, Son SY, Lee CM, Park DJ, Kim HH. Laparoscopic double-tract proximal gastrectomy for proximal early gastric cancer. Gastric Cancer 2014;17:562-70.

31. Sasako $M$, Sano $T$, Yamamoto $S$, Kurokawa $Y$, Nashimoto $A$, Kurita A, et al. D2 lymphadenectomy alone or with para-aortic nodal dissection for gastric cancer. N Engl J Med 2008;359:453-62.

32. Japanese Gastric Cancer Association. Japanese gastric cancer treatment guidelines 2010 (ver. 3). Gastric Cancer 2011;14:113-23.

33. Park DJ, Lee HJ, Lee HS, Kim WH, Kim HH, Lee KU, et al. Sentinel node biopsy for cT1 and cT2a gastric cancer. Eur J Surg Oncol 2006;32:48-54.

34. Park DJ, Kim HH, Park YS, Lee HS, Lee WW, Lee HJ, et al. Simultaneous indocyanine green and $(99 \mathrm{~m}) \mathrm{Tc}$-antimony sulfur colloid-guided laparoscopic sentinel basin dissection for gastric cancer. Ann Surg Oncol 2011;18:160-5.

35. Lee JH, Lee MS, Kim HH, Park DJ, Lee KH, Hwang JY, et al. Feasibility of laparoscopic partial gastrectomy with sentinel node basin dissection in a porcine model. Surg Endosc 2011;25:1070-5.

36. Lee HS, Lee HE, Park DJ, Park YS, Kim HH. Precise pathologic examination decreases the false-negative rate of sentinel lymph node biopsy in gastric cancer. Ann Surg Oncol 2012;19:772-8.

37. Kitagawa $Y$, Takeuchi $H$, Takagi $Y$, Natsugoe $S$, Terashima $M$, Murakami $\mathrm{N}$, et al. Sentinel node mapping for gastric cancer: a prospective multicenter trial in Japan. J Clin Oncol 2013;31:3704-10. 
38. Sugisawa N, Tokunaga M, Makuuchi R, Miki Y, Tanizawa Y, Bando $E_{\text {, }}$ et al. A phase II study of an enhanced recovery after surgery protocol in gastric cancer surgery. Gastric Cancer 2015 Aug 11 [Epub]. http://dx.doi.org/10.1007/s10120-015-0528-6.

39. Lee J, Jeon $\mathrm{H}$. The clinical indication and feasibility of the enhanced recovery protocol for curative gastric cancer surgery: analysis of 147 consecutive experiences. Dig Surg 2014;31:318-23.
40. Ahn SH, Park YS, Jung DH, Son SY, Park DJ, Kim HH, et al. Multimodal ERAS (early recovery after surgery) program in combination with totally laparoscopic distal gastrectomy is the optimal perioperative care in patients with gastric cancer: a prospective randomized clinical trial. Proceedings of the SAGES 2015 Annual Meeting; 2015 April 15-18; Nashville (TN), USA. 